\title{
Spinal cord revealed in free gene map
}

The Allen Institute for Brain Science has released the first data from its ambitious project to map the spinal cord. When completed early next year, the freely accessible atlas will chart the expression patterns of at least 18,500 genes throughout the spinal cord of juvenile and adult mice. The first data, released on 17 July, cover more than 2,000 of those genes.

The atlas is a follow-up to the Allen Brain Atlas, a virtual map of the expression of 20,000 genes in the mouse brain, which was completed in 2006 (E. S. Lein et al. Nature 445, 168-176; 2007). Both projects come courtesy of Paul Allen, co-founder of Microsoft, who has a long-held fascination with brain circuitry.

The latest genetic atlas is being constructed from 20-micrometre-thick sections of spinal cord, taken at millimetre intervals. Researchers will be able to compare gene activity in a four-day-old mouse with that in an adult, and to zoom in on pictures resolvable down to one micrometre per pixel of screen - individual nerve cells are upwards of 10 micrometres in diameter.

"The Allen Brain Atlas, and now the Allen
Spinal Cord Atlas, look comprehensively at what's going on at the cellular level to a degree no one has done before," says Allan Jones, chief scientific officer of the institute, which is based in Seattle, Washington. The \$2.3-million spinal-cord project could yield clues about, for example, the genes involved in neural regeneration $-\$ 600,000$ of the costs came from a coalition that includes the Paralyzed Veterans of America, the US Amyotrophic Lateral Sclerosis (ALS) Association and the US National Multiple Sclerosis Society.

"Motor neurons appear enormous when I zoom in," says neuroscientist Jane Roskams of the University of British Columbia in Vancouver, Canada, who has tried out the atlas. "The images are extremely clear. You can see every single cell, and you can tell the relative positions of cells in different layers," she says. "The resolution is really quite phenomenal, giving the detail you need to assess whether a gene is contributing to the function of a particular cell type."

"It's like looking down on the surface of the Earth and suddenly having the distribution of all the mineral resources beneath the surface revealed to you without having do any digging," says David Anderson of the California Institute of Technology in Pasadena, who is a scientific adviser to the Allen Institute.

Steve McMahon of King's College London, who studies chronic pain mediated by the spinal cord, agrees that the new atlas will be "fantastically useful". But he cautions: "It's an atlas of the normal. It won't tell us about motor neuron disease or multiple sclerosis or chronic pain." In a large number of spinal-cord pathologies, there is a dramatic change in both cell composition and gene expression in the diseased or damaged tissue.

Roskams counters that understanding the spinal cord's healthy state is a necessary first step in trying to fix diseased or injured cells. "If you are going to have a genetic model of ALS that has dying motor neurons and compromised glial cells, and you want to try to restore that model to a healthy state, you've got to have a pretty good idea of what you're restoring it to."

But the most clinically useful information may have to wait for the human project: the institute hopes to complete the Allen Human Brain Atlas by 2012.

Meredith Wadman

\section{Think tank reveals plan to manage tropical forests}

A high-profile group of thinkers has come up with a straightforward way to integrate long-term forest management into an international agreement on halting deforestation.

It is not clear whether the proposal - released on 18 July by the Terrestrial Carbon Group of international scientists, economists and land-policy experts - has political legs.

The idea is to 'lump together' all of the carbon locked up in tropical forests and then allow all countries to cash in on forest protection by trading carbon credits, regardless of whether logging is currently a problem within their borders. The proposal differs from the leading framework under the current United Nations (UN) proposal, which would establish baseline deforestation rates for each country and then allow them to sell carbon credits into an international market if they can reduce the rate of deforestation.

Countries that do not currently have problems with deforestation stand to gain nothing under the UN system, which would mainly benefit countries such as Brazil and Indonesia. Many fear that it could leave the rest of the tropics exposed to logging pressure in the future.

Dan Nepstad, a deforestation expert who is a member of the Terrestrial Carbon Group, says that the group's proposal emphasizes the need for a comprehensive solution for dealing with all tropical forests. "My hope is that it sends a signal to India, Costa Rica, China and other places that there will ultimately be a more robust mechanism that will bring rewards to them," says Nepstad, formerly a scientist at the Woods Hole Research Center in Massachusetts

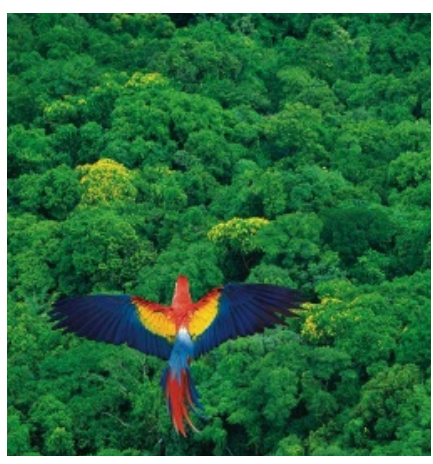

who recently joined the Gordon and Betty Moore Foundation in San Francisco, California, to head its environmental conservation programmes. He is among more than a dozen scientists and economists, including Nobel laureate Joseph Stiglitz of Columbia University, New York, who worked on the proposal, which was organized by the Wentworth Group of Concerned Scientists in Australia. The number of credits that can be sold would be limited each year, guaranteeing a stable, long-term market. And it requires countries to maintain protected areas, including those for which carbon credits have been sold.

Doug Boucher, a deforestation expert with the Union of Concerned Scientists in Washington, calls the approach "novel" but says it introduces a new set of problems, notably that credits could be sold now when the threat of deforestation is decades down the road. He also questions whether negotiators are open to a radical shift in direction at this point. "There's really some strong momentum now," Boucher says. "That's good, but it does tend to limit the possible options." Jeff Tollefson 